\title{
Stigma in patients with bipolar disorders Rumen Milev
}

Address: Department of Psychiatry, Queen's University, Mood Disorders Research and Treatment Service, Providence Care, Mental Health Services, Kingston, Ontario, Canada

from International Society on Brain and Behaviour: 3rd International Congress on Brain and Behaviour

Thessaloniki, Greece. 28 November - 2 December 2007

Published: 17 April 2008

Annals of General Psychiatry 2008, 7(Suppl I):S44 doi:I0.I I86/I744-859X-7-SI-S44

This abstract is available from: http://www.annals-general-psychiatry.com/content/7/SI/S44

(c) 2008 Milev; licensee BioMed Central Ltd.

\section{Background}

Bipolar Disorder is amongst the most common and disabling psychiatric conditions, with chronic course and significant burden of disease. Patients with Bipolar Disorders experience a significant amount of stigmatizing and discrimination because of their illness.

\section{Material and methods}

We have developed an Inventory of Stigmatizing Experiences. It is a questionnaire, which includes both a frequency and an intensity scale, and measures the prevalence and frequency of stigma experiences, with the underlying assumption being that the total score reflects the pervasiveness of stigma experienced across different life domains.

\section{Results}

Over 70 patients attending a specialized tertiary service for patients with Bipolar Disorders were screened with the Inventory of Stigmatizing Experiences. The results show that the experience of stigmatizing events and discrimination because of mental illness is very high and occurs almost universally. Some further analysis based on age, gender and diagnosis is given.

\section{Conclusion}

Stigmatizing experiences and discrimination is common in patients with Bipolar Disorders, and requires work towards reducing it.

\section{References}

I. Stuart H, Milev R, Koller M: The Inventory of Stigmatizing Experience: its development and reliability. World Psychiatry 2005, 4:SI 